\title{
PENGARUH CURRENT RATIO (CR) DAN DEBT TO TOTAL ASSET RATIO (DAR) TERHADAP NET PROFIT MARGIN (NPM) PADA PT. ULTRAJAYA MILK INDUSTRI \& TRADING COMPANY TBK DAN PT. MAYORA INDAH TBK PERIODE 2009 - 2016
}

\author{
Achmad Agus Yasin Fadli ${ }^{1)}$
}

1) dosen universitas pamulang, email : agusfadli70@yahoo.com

ARTICLES

INFORMATION

\section{JURNAL SEKURITAS \\ (Saham, Ekonomi, Keuangan dan Investasi )}

Vol.2, No.1, September 2018 Halaman : $107-118$

C L LPPM \& Prodi Manajemen UNIVERSITAS PAMULANG

ISSN (online) : 2581-2777 ISSN (print) : :2581-2696

Keyword:

Current Ratio (CR), Debt To Asset Ratio (DAR), Net Profit Margin (NPM)

JEL. classification : C31, E50

\section{Contact Author :}

PRODI MANAJEMEN UNPAM

JL.Surya Kencana No.1 Pamulang

Tangerang Selatan - Banten

Telp. (021) 7412566, Fax (021) 7412491 Email :

jurnalfinance.unpam@gmail.com
Tujuan penelitian ini untuk mengetahui pengaruh Current Ratio (CR) dan Debt ToTotal Asset Ratio (DAR) terhadap Net Profit Margin (NPM). Penelitian yang dilakukan dalam penelitian ini bersifat deskriptif dengan pendekatan kuantitatif. Populasi dalam penelitian ini adalah perusahaan sector makanan dan minuman yang terdaftar di Bursa Efek Indonesia. Sampel yang digunakan dalam penelitian ini hanya ada 2 perusahaan. Laporan keuangan yang digunakan berupa neraca dan laporan laba rugi dari tahun 2009 sampai dengan 2016. Data tersebut diperoleh dari website www.idx.co.id. Berdasarkan hasil penelitian yang diperoleh bahwa secara simultan (bersama-sama) terdapat pengaruh yang signifikansi antaravariabel CR dan DAR terhadap variabel NPM. Sedangkan secara parsial variabel CR memiliki pengaruh positif dan signifikan terhadap NPM dan variabel DAR tidak memiliki pengaruh signifikan terhadap NPM. Adjusted R2d alam model regresi sebesar 0.436 atau $43.6 \%$. Sedangkan sisanya sebesar $56.4 \%$ dipengaruhiolehfaktorlainyang tidakdimasukkan dalam model regresi..

The purpose of this study was to determine the effect of Current Ratio (CR) and Debt To Total Asset Ratio (DAR) on Net Profit Margin (NPM). The research conducted in this study is descriptive with a quantitative approach. The population in this study are food and beverage sector companies listed on the Indonesia Stock Exchange. The sample used in this study there are only 2 companies. The financial statements used in the form of balance sheet and income statement from 2009 to 2016. The data was obtained from the website www.idx.co.id. Based on the results of the study, it was found that simultaneously (together) there was a significant influence between $C R$ and $D A R$ variables on NPM variables. While partially the $C R$ variable has a positive and significant effect on NPM and the DAR variable does not have a significant influence on NPM. Adjusted R2d in the regression model is 0.436 or $43.6 \%$. While the remaining $56.4 \%$ is influenced by other factors not included in the regression model. 


\section{A. Pendahuluan}

Bisnis adalah suatu kegiatan yang menjadi tolak ukur kemajuan suatu negara yang dapat dilihat dari kemajuan ekonominya dan merupakan tulang punggung dari kemajuan ekonomi. Kegiatan bisnis merupakan salah satu faktor persaingan yang paling memberikan pengaruh besar diantara perusahaan yang ada. Hal ini dikarenakan bahwa setiap perusahaan berlomba-lomba agar mendapatkan keuntungan yang besar dibanding perusahaan lainnya. Di mana perusahaan didirikan dengan tujuan meningkatkan nilai perusahaan sehingga dapat memberikan kemakmuran bagi pemilik atau para pemegang saham. Salah satu upaya untuk mencapai tujuannya, perusahaan selalu berusaha memaksimalkan laba.

Persaingan bisnis antar perusahaan maupun antar negara dilakukan secara bebas dan ketat karena banyak bermunculan perusahaan asing di dalam negeri yang disebabkan semakin tipisnya batas antar negara. Persaingan dalam usaha dan menipisnya batas antar negara ini membawa pengaruh yang besar bagi perusahaan pada suatu negara untuk dapat bersaing dengan perusahaan lainnya yang ada di dalam negeri maupun perusahaan asing lainnya. Untuk mengatasi persaingan tersebut maka salah satu cara yang digunakan dengan cara menunjukkan kinerja perusahaan yang baik dimata publik pada umumnya dan pada investor pada khususnya.

Laporan keuangan adalah laporan yang menunjukan kondisi keuangan perusahaan pada saat ini maupun dalam suatu periode tertentu (Kasmir, 2015:7). Dalam praktiknya laporan keuangan merupakan alat yang sangat penting untuk memperoleh informasi sehubungan dengan posisi keuangan dan hasil-hasil yang telah dicapai oleh perusahaan atau hasil kinerja perusahaan untuk mereka yang berkepentingan dengan perusahaan tersebut. Dalampraktiknya dikenal beberapa macam laporan keuangan seperti laporan neraca, laba rugi, arus kas, perubahan modal dan catatan atas laporan keuangan. Semualaporan keuangan tersebut diatas secara garis besar menggambarkan kondisiperusahaan yang memudahkan berbagai pihak yang berkepentingan dalam menilaikinerja perusahaan. Mereka yang mempunyai kepentingan terhadap perkembangan suatu perusahaan tersebut perlu mengetahui salah satu faktor terpenting yang harus diperhatikan yaitu profitabilitas perusahaan.

Salah satu sarana yang sering digunakan dalam mengukur tingkat kinerja keuangan adalah analisis rasio keuangan. Analisis rasio keuangan merupakan instrumen analisis prestasi perusahaan yang menjelaskan berbagai hubungan dan indikator keuangan, yang ditujukan untuk menggambarkan perubahan dalam kondisi keuangan atau menggambarkan prestasi perusahaan yang menunjukkan risiko dan peluang yang ada pada perusahaan tersebut. Ada beberapa jenis rasio keuangan yang dapat menunjukkan kinerja keuangan perusahaan. Diantaranya adalah rasio likuiditas, rasio solvabilitas, rasio aktivitas serta rasio profitabilitas. Kemajuan perekonomian di Indonesia cukup besar ditunjang oleh adanya perkembangan perusahaan industri yang bergerak pada bidang makanan dan minuman kemudian dijual guna memperoleh profit yang besar. Industri makanan dan minuman dihadapkan pada suatu keputusan penting untuk meningkatkan kemampuanya dalam memperoleh laba. Untuk mencapai tujuan tersebut diperlukan pengelolaan manajemen dengan tingkat efektivitas yang tinggi. Oleh sebab itu, industri makanan dan minuman harus menjaga kinerja perusahaanya agar dapat diketahui seberapa besar rasio profitabilitas yang dimiliki.

Rasio profitabilitas merupakan rasio untuk menilai kemampuan perusahaan dalm mencari keuntungan untuk memberikan tingkat efektifitas manejemen suatu perusahaan yang ditunjukan oleh laba yang dihasilkan dari penjualan dan pendapatan investasi (Kasmir, 2015:196). Dalam rasio ini terdiri atas gross profit margin (GPM), operatingincome ratio, operating ratio, return on investment $(R O I)$, nett profit margin(NPM), return on assets (ROA), dan return on equity (ROE). Dari indikator 
didalam rasio profitabilitas tersebut, dimana nett profit margin(NPM) yang menjadiindikator dalam menunjukkan tingkat profitabilitas.

Keberhasilan perusahaan terletak pada berhasil tidaknya perusahaan dalam memasarkan barang guna mendapat keuntungan yang optimal, di mana semakin besar laba yang diperoleh perusahaan semakin besar pula perusahaan dapat menutupi tingkat likuiditasnya. Likuiditas adalah kemampuan suatu perusahaan untuk memenuhi kewajiban jangka pendeknya secara tepat waktu. Jika perusahaan mampu membayar semua kewajibannya maka perusahaan dalam keadaan likuid (Fahmi, 2014:69).

Likuiditas dapat diukur dengan menggunakan beberapa cara. Secara umumada lima jenis rasio likuiditas yang dominan dipakai dalam penelitian yaitucurrent ratio (rasio lancar), rasio cepat (quick ratio), rasio kas (cash ratio), rasioperputaran kas, dan inventory net working capital (Kasmir, 2015 : 134). Indikator dalam penelitian ini mengunakan current ratio (rasio lancar) untuk menilai tingkat likuiditas perusahaan yang hubunganya denganmasalah kemampuan perusahaan untuk memenuhi kewajiban finansial jangkapendeknya yang harus segera dipenuhi (Sawir, $2009: 104)$.

Keberhasilan perusahaan juga dapat diukur dengan menggunakan rasio solvabilitas. Salah satunya dengan menggunakan Debt to Total AssetsRatio yang juga memiliki pengaruh pada laba perusahaan. Dimana rasio solvabilitas adalah mengukur sejauh mana aktiva perusahaan dibiayai dengan hutang. Artinya, berapa besar beban utang yang ditanggung perusahaan dibandingkan dengan aktivanya (Kasmir, 2015:151).

Objek perusahaan yang digunakan dalam penelitian ini adalah perusahaanyang masuk dalam Bursa Efek Indonesia (BEI) yang tergolong dalamsektor industri barang konsumsi, lebih tepatnya pada PT. Ultrajaya Milk Industri \& Trading Company, Tbk dan PT. Mayora Indah, Tbk yang merupakan perusahaan subsektormakanan dan minuman dikarenakan dalam perusahaan makanan dan minuman ini,selain dari investasinya yang aman karena sudah memenuhi syarat dan ketentuan,dari subsektor ini juga banyak orang yang memanfaatkan keberadaannyadikarenakan makanan dan minuman merupakan kebutuhan pokok manusia untuksetiap harinya.

Berikut hasil likuiditas, solvabilitas dan profitabilitas dengan menggunakan indikator Current ratio, Debt to total assets ratio dan Net Profit Margin pada PT. Ultrajaya Milk Industri \& Trading Company, Tbk dan PT. Mayora Indah, Tbk periode 2009-2016.

Tabel 1.1

Rata-rata CR, DAR dan NPM pada PT Ultrajaya Milk Industri \& Trading Company, Tbk dan PT. Mayora Indah, Tbk periode 2009-2016.

\begin{tabular}{|l|l|l|l|l|}
\hline \multirow{2}{*}{ No } & \multirow{2}{*}{ Tahun } & \multicolumn{3}{|c|}{ RASIO } \\
\cline { 3 - 5 } & & CR & DAR & NPM \\
\hline 1 & 2009 & 220 & 41 & 6 \\
\hline 2 & 2010 & 229 & 44 & 8 \\
\hline 3 & 2011 & 187 & 51 & 5 \\
\hline 4 & 2012 & 239 & 47 & 10 \\
\hline 5 & 2013 & 244 & 44 & 9 \\
\hline 6 & 2014 & 272 & 41 & 5 \\
\hline
\end{tabular}




\begin{tabular}{|l|l|l|l|l|}
7 & 2015 & 306 & 38 & 10 \\
\hline 8 & 2016 & 374 & 35 & 12 \\
\hline
\end{tabular}

(Dalam persen)

Sumber:Data diolah 2018 (http://www.idx.co.id),

Berdasarkan Tabel 1.1 yakni dilihat dari persentase current ratio(CR) yang menunjukan bahwa untuk 2009-2016 mengalami kenaikan dan penurunan yang tidak stabil setiap tahunnya. Kemudian tingkat ketidakstabilan Debt to total assets rasio (DAR) terjadi ditahun 2009-2011 kemudian mulai tahun 2012-2016 tingkat DAR mengalami penurunan setiap tahunnya, sedangkan laba bersih atau Net profit margin (NPM) pada tahun 2009-2014 mengalami kondisi yang kurang membaik, namun pada tahun 2015-2016 kondisi perusahaan lebih baik.

Berdasarkan keterangan diatas maka dapat disimpulkan bahwasanya CR, DAR, dan NPMpada perusahaan-perusahaan tersebut diatas mengalami kenaikan dan penurunanyang dimana hal tersebut menjadi permasalahan yang harus diperhitungkan olehperusahaan. Dikarenakan Net Profit Margin (NPM)itu sendiri adalah rasio untuk mengukur keuntungan dengan membandingkan antara laba setelah bunga dan pajak dibandingkan dengan penjualan. Jadi jika suatu perusahaan mempunyai NPMyang tinggi maka perusahaan tersebut berpeluang besar dalam meningkatkanpertumbuhan. Tetapi jika laba mengalami penurunan maka perusahaan perlu mencari tahu penyebabnya karena akan membahayakan perusahaan dan menghambat pertumbuhan.

Dari uraian di atas diketahui bahwa Current Ratio, Debt to Total Assets Ratio berpengaruh pada laba perusahaan yang diukur dengan Net Profit Margin. Dengan bertambah tingginya kinerja perusahaan yang diukur dengan rasio Net Profit Margin, maka diharapkan semakin tinggi pula kemampuan perusahaan untuk mencapai tujuan dalam menghasilkan laba yang diharapkan. Dengan demikian berdasarkan latar belakang masalah diatas, penulis tertarik untuk melakukan penelitian dan mengambil judul "Pengaruh Current Ratio dan Debt to Total Assets Ratio Terhadap Net Profit Margin pada PT. Ultrajaya Milk Industri \& Treding Company, Tbk dan PT. Mayora Indah, Tbk periode 2009-2016".

\section{B. Perumusan Masalah}

1. Bagaimana pengaruh Current Ratio (CR) terhadap Net Profit Margin (NPM) pada PT.Ultrajaya Milk Industri \& Trading Company Tbk dan PT.Mayora Indah Tbk periode 2009-2016?

2. Bagaimana pengaruh Debt to Total Asset Ratio (DAR) terhadap Net Profit Margin (NPM) pada PT.Ultrajaya Milk Industri \& Trading Company Tbk dan PT.Mayora Indah Tbk periode 2009-2016?

3. Bagaimana pengaruh Current Ratio (CR) dan Debt to Total Asset Ratio (DAR) secara bersama-sama terhadap Net Profit Margin (NPM) pada PT.Ultrajaya Milk Industri \& Trading Company Tbk dan PT.Mayora Indah Tbk periode 20092016 ?

\section{Tujuan Penelitian}

1. Untuk mengetahui pengaruh Current Ratio (CR) terhadap Net Profit Margin (NPM) pada PT.Ultrajaya Milk Industri \& Trading Company Tbk dan PT.Mayora Indah Tbk periode 2009-2016?

2. Untuk Mengetahui pengaruh Debt to Total Asset Ratio (DAR) terhadap Net Profit Margin (NPM) pada PT.Ultrajaya Milk Industri \& Trading Company Tbk dan PT.Mayora Indah Tbk periode 2009-2016? 
3. Untuk mengetahui pengaruh Current Ratio (CR) dan Debt to Total Asset Ratio (DAR) secara bersama-sama terhadap Net Profit Margin (NPM) pada PT.Ultrajaya Milk Industri \& Trading Company Tbk dan PT.Mayora Indah Tbk periode 2009-2016?

\section{Landasan Teori Manajemen}

Manajemen berasal dari bahasa inggris yaitu manage yang berarti mengurus, mengelola, mengendalikan, mengusahakan, memimpin. Pengertian manajemen secara etimologis adalah seni melaksanakan dan mengatur. Manajemen dapat dipandang sebagai disiplin ilmu yang mengajarkan proses untuk mendapatkan tujuan organisasi dalam upaya bersama dengan sejumlah orang atau sumber yang dimiliki organisasi.

Manajemen merupakan seni dalam menyelesaikan pekerjaan melalui kerja sama dengan orang lain.

\section{Keuangan}

Keuangan merupakan segala sesuatu yang berhubungan dengan uang untuk dikelola secara teroganisasi yang nantinya dapat memenuhi setiap tujuan yang akan dicapai.

\section{Manajemen Keuangan}

Manajemen keuangan merupakan penggabungan dari ilmu dan seni yang membahas, mengkaji dan menganalisis tentang bagaimana seorang manajer keuangan dengan mempergunakan seluruh sumber daya perusahaan untuk mencari dana, mengolah dana, dan membagi dana dengan tujuan mampu memberikan profit atau keuntungan bagi para pemegang saham dan suistainability (berkelanjutan) usaha bagi perusahaan.

\section{Laporan Keuangan}

Laporan keuangan ialah produk akhir dari sebuah pelaporan transaksi keuangan yang penyusunannya diatur oleh standar atau aturan ilmu akuntansi, insentif manager, mekanisme pelaksanaan dan pengawasan perusahaan.Pengetahuan dan pemahaman lingkungan pelaporan keuangan yang baik sangat mendukung dalam penyampaian informasi posisi keuangan perusahaan sesungguhnya agar dicapai kinerja perusahaan yang lebih baik.

Dalam praktiknya, secara umum ada lima macam jenis laporan keuangan yang biasa disusun, yaitu neraca, laporan laba/rugi, laporan perubahan modal, laporan arus kas dan laporan catatan atas laporan keuangan.

\section{Current Ratio (CR)}

Current ratio merupakan rasio untuk mengukur kemampuan perusahaan dalam membayar kewajiban jangka pendek atau hutang yang segera jatuh tempo pada saat ditagih secara keseluruhan.

Perhitungan rasio lancar dilakukan dengan cara membandingkan antara total aktiva lancar dengan total hutang lancar. Rumus untuk mencari rasio lancar adalah sebagai berikut:

$$
\begin{aligned}
& \text { Current Ratio }=\underline{\text { Aktiva }} \\
& \underline{\text { lancar }} \times 100 \%
\end{aligned}
$$

Utang lancar

Dari hasil pengukuran rasio, apabila rasio lancar rendah, dapat dikataan bahwa perusahaan kurang modal untuk membayar utang. 
Namun, apabila hasil rasio tinggi, belum tentu perusahaan dalam kondisi baik. Bisa saja hal ini terjadi karena kas tidak digunakan dengan sebaik mungkin.

\section{Debt to Total Asset Ratio (DAR)}

Debt to Total Assets Ratio menurut Kasmir (2015:156) merupakan rasio utang yang digunakan untuk mengukur perbandingan antara total utang dengan total aktiva.

Sehingga dapat disimpulkan bahwa rasio ini mengukur presentasebesarnya dana yang berasal dari hutang baik jangka pendek maupun jangkapanjang. Kreditur lebih menyukai Debt to Total Assets Ratio atau DebtRatio yang rendah sebab tingkat keamanannya semakin baik. Untuk mengukurbesarnya Debt to Total Assets Ratio dapat dihitung dengan rumus sebagaiberikut :

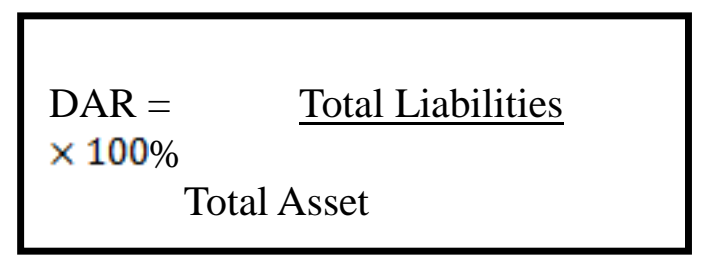

\section{Net Profit Margin (NPM)}

Net Profit Margin merupakan salah satu rasio yang digunakan untuk mengukur margin laba atas penjualan. Semakin tinggi Net Profit Margin maka investor semakin menyukaiperusahaan tersebut karena menunjukkan bahwa perusahaan mendapatkan hasilyang baik melebihi harga pokok penjulan. Adapun rumus rasio Net Profit Marginsebagai berikut:

$$
\begin{gathered}
\mathrm{NPM}=\frac{\text { Laba Bersih }}{\times 100 \%} \\
\text { Penjualan Bersih }
\end{gathered}
$$

\section{E.Metode Penelitian}

Dalam penelitian ini, peneliti menggunakan pendekatan kuantitatif dengan menggunakan analisis regresi berganda untuk mengetahui apakah terdapat pengaruh yang signifikan antara variabel independen yaitu Current Ratio (CR), Debt to Total Assets Ratio (DAR) terhadap variabel dependen yaitu pertumbuhan laba. Setelah data diperoleh, data akan diolah, dianalisis, dan diproses lebih lanjut sesuai dengan teori dan literatur terkait kemudian akan ditarik kesimpulan. Penelitian yang dipilih untuk memperoleh data dan informasi dalam penulisan skripsi ini, yaitu dengan melakukan penelitian pada perusahaan yang terdaftar di Bursa Efek Indonesia dengan nama lain Indonesia Capital Market Electronic Library (ICAMEL) yang beralamat di Jl. Jenderal Sudirman Kav. 52 - 53 Jakarta 12190.Sampel dalam penelitian ini merupakan laporan keuangan tahunan PT. Ultrajaya Milk Industri \& Trading Company, Tbk dan PT. Mayora Indah, Tbk yang terdiri dari neraca dan laporan laba rugi pada tahun 2009-2016.

Teknik analisis data yang digunakan antara lain, (1) Statistik deskriptif meliputi nilai minimum, nilai maksimum, mean dan standar deviasi, (2) Uji Prasyarat analisis menggunakan uji asumsi klasik meliputi uji heteroskedastisitas, ujimultikolinieritas,uji normalitas, uji (3) Pengujian hipotesis meliputi uji parsial (uji t) dan uji simultan (uji f), analisis regresi linier berganda, dan koefesien determinasi. 


\section{F.Hasil Penelitian Dan Pembahasan}

Hasil olah data SPSS v.21 statistik deskriptif dapat dilihat pada tabel 4.1 sebagai berikut:

Tabel 4.1

Statistik Deskriptif CR, DAR dan NPM

\section{Descriptive Statistics}

\begin{tabular}{|l|r|r|r|r|r|}
\hline & \multicolumn{1}{|c|}{ N } & Minimum & Maximum & \multicolumn{1}{|c|}{ Mean } & Std. Deviation \\
\hline Current Ratio & 16 & 148 & 484 & 280.92 & 101.072 \\
Debt to Total & 16 & 18 & 63 & 42.42 & 16.182 \\
Asset Ratio & 16 & 3 & 15 & 7.87 & 3.203 \\
Net Profit & 16 & & & & \\
Margin & & & & & \\
Valid N (listwise) & 16 & & & \\
\hline
\end{tabular}

Dari tabel 4.1 terlihat bahwa selama periode 2009-2016 CR memilikinilai terendah (minimum) sebesar 148, sedangkan nilai tertinggi(maksimum) sebesar 484 . Nilai rata-rata selama periode 2009-2016 adalahsebesar 280.92 dengan standar deviasi (std deviation) sebesar 101.072 yangmengindikasikan bahwa variabel CR mempunyai sebaran kecil karenastandar deviasi lebih kecil dari pada nilai rata-rata, sehingga simpangan datapada variabel CR dapat dikatakan baik.

Sedangkan DAR nilai rata-ratanya (mean) adalah 42.42 dengan standar deviasi 16.182 yang mengindikasikan bahwavariabel DAR mempunyai sebaran kecil karena standar deviasi lebih kecildari pada nilai rata-rata, sehingga simpangan data pada variabel DAR dapatdikatakan baik.

Nilai rata-rata NPM selama periode 2009-2016 adalahsebesar 7.87 dengan standar deviasi (std deviation) sebesar 3.203 yangmengindikasikan bahwa variabel NPM mempunyai sebaran kecilkarena standar deviasi lebih kecil dari pada nilai rata-rata, sehinggasimpangan data pada variabel NPM dapat dikatakan baik.

\section{F.1 Hasil Analisis}

Berikut ini merupakan hasil pengolahan data denganmenggunakan bantuan program SPSS 21, selengkapnya dapat dilihat padatabel 4.2.

Tabel 4.2

Hasil Uji Regresi Berganda

\section{Coefficients $^{\mathrm{a}}$}

\begin{tabular}{|l|c|c|c|c|c|}
\hline Model & \multicolumn{2}{|c|}{$\begin{array}{c}\text { Unstandardized } \\
\text { Coefficients }\end{array}$} & $\begin{array}{c}\text { Standardized } \\
\text { Coefficients }\end{array}$ & $\mathrm{t}$ Sig. \\
\cline { 2 - 4 } & $\mathrm{B}$ & $\begin{array}{c}\text { Std. } \\
\text { Error }\end{array}$ & Beta & & \\
\hline
\end{tabular}




\begin{tabular}{|ll|r|r|r|r|r|}
\hline & (Constant) & 4.763 & 3.615 & & 1.317 & .210 \\
& .021 & .009 & .537 & 2.411 & .031 \\
Current Ratio & -.055 & .044 & -.278 & -1.248 & .234 \\
\hline
\end{tabular}

a. Dependent Variable: Net Profit Margin

Sumber: Data diolah SPSS 21, 2018

Berdasarkan nilai konstanta dan koefisien regresitersebut, maka hubungan antara variabel-variabel independen denganvariabel dependen dalam model regresi dapat dirumuskan sebagai berikut:

$\mathrm{Y}=4.763+0.21 \mathrm{X}_{1}-0.55 \mathrm{X}_{2}+\mathrm{e}$

Dari persamaan model regresi linier tersebut dapat dijelaskan sebagai berikut:

$>$ Konstanta (a)

Nilai konstanta (a) sebesar 4.763 ini dapat diartikan jika CR dan DAR nilainya 0, maka NPM nilainya 4.763 satuan.

$>$ Koefesien $\mathrm{CR}\left(\mathrm{X}_{1}\right)$

Nilai koefisien $\mathrm{CR}$ adalah sebesar 0.21 . Nilai $\mathrm{CR}$ yang positif menunjukkan adanya hubungan positif antara variabel CR denganNPM.

$>$ Koefesien DAR $\left(\mathrm{X}_{2}\right)$

Nilai koefisien DAR adalah sebesar -0.55. Nilai DAR yangnegatif menunjukkan adanya hubungan negatif antara variabel DAR dengan NPM.

\section{F.2 Pengujian Hipotesis}

\section{Uji Parsial (Uji t)}

Pengujian ini dilakukan untuk mengetahui signifikansi peran secara parsial antara variabel independen terhadap variabel dependen denganmengasumsikan bahwa variabel independen lain dianggap konstan.

\section{Tabel 4.3 \\ Hasil Uji T (T-Test) Parsial \\ Coefficients $^{\mathrm{a}}$}

\begin{tabular}{|c|c|c|c|c|c|}
\hline \multirow[t]{2}{*}{ Model } & \multicolumn{2}{|c|}{$\begin{array}{c}\text { Unstandardized } \\
\text { Coefficients }\end{array}$} & \multirow{2}{*}{$\begin{array}{c}\begin{array}{c}\text { Standardized } \\
\text { Coefficients }\end{array} \\
\text { Beta }\end{array}$} & \multirow[t]{2}{*}{$\bar{T}$} & \multirow[t]{2}{*}{ Sig. } \\
\hline & $B$ & $\begin{array}{l}\text { Std. } \\
\text { Error }\end{array}$ & & & \\
\hline (Constant) & 4.763 & 3.615 & & 1.317 & .210 \\
\hline Current Ratio & .021 & .009 & .537 & 2.411 & .031 \\
\hline $\begin{array}{l}\text { Debt to Total } \\
\text { Asset Ratio }\end{array}$ & -.055 & .044 & -.278 & -1.248 & .234 \\
\hline
\end{tabular}

a. Dependent Variable: Net Profit Margin

Sumber: Data diolah SPSS 21, 2018

Besarnya angka $t_{\text {tabel }}(\alpha / 2 ; d f)$ dengan ketentuan $\alpha=(0,05 / 2)=0,025$ dan $d f=(n-k-$ 
1) atau(16-2-1) $=13$ sehingga diperoleh nilai $t_{\text {tabel }}$ sebesar 2.160 . BerdasarkanTabel 4.3 diatas, maka dapat diketahui pengaruh masing-masing variabelsebagai berikut:

$>$ Variabel CR terhadap NPM

Dari tabel coefficients diperoleh nilai $t_{\text {hitung }}=2.411$ yang artinya $t_{\text {hitung }}>t_{\text {tabel }}$ $(2.411>2.160)$ dengan signifikansi $0.031<0,05$ maka Ho ditolak dan $\mathrm{Ha}$ diterima artinya secara parsial terdapat pengaruhsignifikan antara CR terhadap NPM.

$>$ Variabel DAR terhadap NPM

Dari tabel coefficients diperoleh nilai $t_{\text {hitung }}=-1.248$ yang artinya $t_{\text {hitung }}<t_{\text {tabel }} \quad(-$ $1.577<2.160$ ) dengan signifikansi 0.234> 0,05 maka Ho diterima dan $\mathrm{Ha}$ ditolak artinya secara parsial tidak terdapat pengaruhsignifikan antara DAR terhadap NPM.

\section{F.3 Uji F (Simultan)} berikut:

Berikut ini merupakan hasil dariUji-F yang dapat dilihat pada tabel 4.4 sebagai

Tabel 4.4

Hasil Uji F (F-Test) Simultan

ANOVA $^{a}$

\begin{tabular}{|c|c|c|c|c|c|}
\hline Model & $\begin{array}{l}\text { Sum of } \\
\text { Squares }\end{array}$ & $\overline{D f}$ & Mean Square & $\mathrm{F}$ & Sig. \\
\hline $\begin{array}{l}\text { Regression } \\
\text { Residual } \\
\text { Total }\end{array}$ & $\begin{array}{r}78.663 \\
75.190 \\
153.853\end{array}$ & $\begin{array}{r}2 \\
13 \\
15\end{array}$ & $\begin{array}{r}39.332 \\
5.784\end{array}$ & 6.800 & $.010^{b}$ \\
\hline
\end{tabular}

a. Dependent Variable: Net Profit Margin

b. Predictors: (Constant), Debt to Total Asset Ratio, Current Ratio

Sumber: Data diolah SPSS 21, 2018

Jika $F_{\text {hitung }}>F_{\text {tabel, }}$, maka Ho ditolak dan $H_{a}$ diterima dan sebaliknya $F_{\text {hitung }}<F_{\text {tabel }}$, maka $\mathrm{H}_{\mathrm{o}}$ diterima dan $\mathrm{Ha}$ ditolak.Berdasarkan Tabel 4.4diperoleh nilai $\mathrm{F}_{\text {hitung }}$ sebesar $6.800>\mathrm{F}_{\text {tabel }}$ sebesar 3.74 sehingga $\mathrm{H}_{\mathrm{O}}$ ditolak dan $\mathrm{Ha}$ diterima dengan signifikansi $0.010<0.05$ (yang ditetapkan), maka dapat diartikan bahwa secara simultan(bersama-sama) terdapat pengaruhyang signifikansi antara variabel CR dan DAR terhadap variabelNPM.

\section{F.4 Koefesien Determinasi}

Koefisien determinasi digunakan untuk menguji seberapa besarperanan variabel independen untuk menjelaskan variabilitas variabeldependen dalam model regresi. 
Tabel 4.5

Hasil Uji Koefisien Determinasi $\left(\mathbf{R}^{2}\right)$

Model Summary

\begin{tabular}{|l|r|r|r|r|}
\hline Model & \multicolumn{1}{|c|}{$\mathrm{R}$} & R Square & \multicolumn{1}{|c|}{$\begin{array}{c}\text { Adjusted R } \\
\text { Square }\end{array}$} & \multicolumn{2}{|c|}{$\begin{array}{c}\text { Std. Error of the } \\
\text { Estimate }\end{array}$} \\
\hline 1 & $.715^{\mathrm{a}}$ & .511 & .436 & 2.405 \\
\hline
\end{tabular}

a. Predictors: (Constant), Debt to Total Asset Ratio, Current Ratio

Sumber: Data olah SPSS 21, 2018

Dari tabel 4.5 diatas hasil uji koefisien determinasi diperoleh nilaikorelasi $(R$ Square) sebesar 0.436 atau $43.6 \%$ yang menunujukkan bahwa Current Ratio dan Debt toTotal Asset Ratio berpengaruh terhadap Net Profit Margin sebesar $43.6 \%$. Sedangkan sisanya $(100 \%-43.6 \%=56.4 \%)$ dipengaruhi oleh variabel lain diluar penelitian.

\section{G.Kesimpulan}

\section{Kesimpulan}

Berdasarkan hasil analisis data dan pembahasan yang diuraikan, dapat ditarik kesimpulan sebagai berikut :

1. Hasil pengujian hipotesis secara simultan (uji F) menunjukan bahwa nilai $F_{\text {hitung }}$ sebesar $6.800>F_{\text {tabel }}$ sebesar 3.74 dengan signifikansi $0.010<0.05$ (yang ditetapkan), sehingga bahwa secara simultan (bersama-sama) terdapat pengaruh yang signifikansi antara variabel CR dan DAR terhadap variabel NPM.

2. Berdasarkan hasil pengujian hipotesis secara parsial (uji T) dapat disimpulkan bahwa:

a) Variabel CR terhadap NPM

Variabel Current Ratio (CR) berpengaruh positif dan signifikan terhadap Net Profit Margin (NPM).

b) Variabel DAR terhadapNPM

Variabel Debt to Total Asset Ratio (DAR) tidak berpengaruh signifikan terhadap Net Profit Margin (NPM).

3. Hasil uji koefisien determinasi diperoleh nilai korelasi (R) sebesar0.436 atau 43.6\% yang menunujukkan bahwa Current Ratio dan Debt to Total Asset Ratio berpengaruh terhadap Net Profit Margin sebesar $43.6 \%$ dan memiliki korelasi yang positif, artinya apabila CR dan DAR secara bersama-sama mengalami peningkatan, maka NPM juga akan meningkat. 


\section{Saran}

Berdasarkan dari hasil penelitian yang telah dilakukan, berikut merupakan saran-saran yang dapat peneliti berikan:

1. Bagi Perusahaan

a) Perusahaan harus mampu mempertahankan dan meningkatkan efektiitas dalam hal pengelolaan aktivanya.

b) Perusaghaan perlu memperhatikan peningkatan Current Ratio dan Debt to Total Asset Ratio untuk menigkatkan dan memperbaiki Net Profit Margin perusahaan dimasa akan datang, sehingga dapat menambah laba serta menarik lebih banyak investor.

2. Bagi Investor

Bagi investor yang akan melakukan investasi disarankan dapat terlebih dahulu memperhatikan kemampuan perusahaan tersebut dalam menghasilkan profit serta dapat memahami perubahan masing-masing rasio keuangan pada laporan keuangan yang disediakan perusahaan.

3. Bagi peneliti yang akan datang

a) Bagi peneliti selanjutnya disarankan agar dapat menggunakan periode pengamatan yang lebih lama untuk mendapatkan hasil yang lebih akurat.

b) Bagi peneliti dimasa mendatang hendaknya melakukan penelitian dengan jumlah rasio keuangan yang lain dan metode lain, sehingga dapat meningkatkan kualitas hasil penelitian.

c) Bagi peneliti selanjutnya hendaknya menggunakan jumlah rasio yang lebih banyak dari rasio yang sekarang, hal ini bertujuan memberikan gambaran hasil penelitian secara maksimal.

\section{H.DAFTAR PUSTAKA}

\section{BUKU}

Brigham, Eugene F.dan Joul F Houston, "Dasar-dasar Manajemen Keuangan", Salemba Empat, Jakarta, 2014.

Fahmi, Irham, “Analisis Laporan Keuangan”, Edisi 3., Alfabeta, Bandung, 2014.

Ghozali, Imam, "Aplikasi Analisis Multivariate Dengan Program IBM SPSS 21", Edisi 7., Universitas Diponegoro, Semarang, 2013.

Hasibuan, Malayu S.P., "Manajemen : Dasar, Pengertian dan Masalah", Bumi Aksara, Jakarta, 2015.

Horne, James C. Van dan John M Wachowicz, Jr, "Prinsip-Prinsip Manajemen Keuangan", Edisi 13., Salemba Empat, Jakarta, 2012.

Kasmir, "Analisis Laporan Keuangan”, Edisi 1-8., Rajawali Pers, Jakarta, 2015.

Martono dan Agus Harjito,"Manajemen Keuangan”,Edisi 3.,Ekonisia, Yogyakarta, 2010.

Sugiyono, "Metode Penelitian Kuantitatif, Kualitatif, dan R\&D"., Alfabeta, Bandung, 2016.

Sundjaja, Ridwan, Inge Barlian, dan Dharma Putra Sundjaja, "Manajemen Keuangan 2", Edisi 6., Literata Lintas Media, Jakarta, 2010. 
Prastowo, Dwi dan Rifka Juliaty, "Analisis Laporan Keuangan: Konsep dan Aplikasi, Edisi 3., UPP STIM YKPN, Yogyakarta,2010.

\section{JURNAL}

Fercanza, Vando, "Pengaruh Current Ratio, Total Debt To Total Assets, dan Sales Growth Terhadap Net Profit Margin pada Perusahaan Batu Bara yang Terdaftar Di Bursa Efek Indonesia", Jurnal Vol 8, No 2, 2016.

Nardi Sunardi (2017) Determinan Kebijakan Utang Serta Implikasinya terhadap Kinerja Perusahaan (Perusahaan yang tergabung dalam indeks LQ.45 yang terdaftar di Bursa Efek Indonesia Tahun 2011- 2015) Jurnal Sekuritas, Vol. 1, No.1 / September 2017 Universitas Pamulang.

Nardi Sunardi 2018, Analisis Du Pont System Dengan Time Series Approach (Tsa) Dan Cross Sectional Approach (Csa) Dalam Penilaian Kinerja Keuangan Perusahaan (Studi Pada Industri Konstruksi (BUMN) di Indonesia Yang Listing di BEl Tahun 2013-2017), Jurnal Sekuritas (Saham, Ekonomi, Keuangan dan Investasi) Vol.1, No.4, Juni 2018, Halaman : $1-15$, Unversitas Pamulang.

Nardi Sunardi, Aceng Abdul Hamid, Lativa, Abdul Kadim, Natanael Tulus (2018) Determinant Of Cost Efficiency And It's Implications For Companies Performance Incorporated In The Lq.45 Index Listing In Idx For The Period of 2011-2016, International Journal of Applied Business and Economic Research,.Volume 16, Number 1, 2018, ISSN : 0972-7302

Liza, Erosa Pitria, "Pengaruh Current Ratio dan Total Debt to Total Assets Ratio terhadap Net Profit Margin Pada Perusahaan Food and Beverage yang terdaftar di BEl tahun 2008-2012", Universitas Widyatama, Bandung, 2013.

Putri, Deviana Della, "Analisis Pengaruh Likuiditas dan Leverage Terhadap Net Profit Margin pada Perusahaan Industri Plastik yang Terdaftar di Bursa Efek Indonesia", Jurnal Vol 1, No 1, 2012.

Prakosa, Wahidi Ribud, "Pengaruh Likuiditas dan Solvabilitas Terhadap Profotabilitas studi pada perusahaan Makanan dan Minuman yang terdaftar di ISSI 20122016", Institut Agama Islam Negeri Surakarta, 2016.

Wahnida, Selva, "Pengruh Current Ratio, Debt to Asset Ratio dan Return On Equity Terhadap Harga Saham Perusahaan Pada Sektor Pertanian Dalam Kelompok ISSI", Universitas Islam Negri Raden Fatah, Palembang, 2017.

Wicaksono, Hendra Adhitiya, "Pengaruh current ratio, debt to asset ratio, ttotal asset turnover, return on equity, suku bunga, kurs valuta asing, inflasi,dank as deviden terhadap harga saham perusahaan makanan danminuman yang terdaftar di BEl periode 2009-2011", Skripsi, 2014 (tidakditerbitkan).

WEB

www.idx.co.id

http://mayoraindah.co.id/

http://www.ultrajaya.co.id/ 